\title{
THE RELATIONSHIP BETWEEN PRESCRIPTION PATTERN AND DRUG COST AT COMMUNITY HEALTH CENTER AND PRATAMA CLINIC IN THE NATIONAL HEALTH INSURANCE PROGRAM
}

\author{
Yeni'), Mardiati Nadjib²) \\ 1)Faculty of Public Health, Universitas Indonesia \\ ${ }^{2)}$ Department of Health Policy Administration, Faculty of Public Health, \\ Universitas Indonesia
}

\begin{abstract}
Background: In the National Health Insurance (NHI) era, the payment system at Primary Health Care (PHC) changed from direct payment (out of pocket payment) to pre-paid system (capitation). The amount of capitation varied by PHC type, with drug as a financing component of capitation. The prescription pattern will affect the amount of drug cost. This study aimed to investigate the relationship between prescription pattern and drug cost at community health center (Puskesmas) and Pratama clinic in NHI program.

Subjects and Method: A cross-sectional study was conducted at a Puskesmas and a Pratama clinic in Bandung, West Java. A total of 800 prescriptions was selected for this study. The dependent variable was prescription pattern. The independent variables were drug cost, and national formulary. The secondary data were collected from the study of drug cost at PHC conducted by the Ministry of Health in 2017. The data were analyzed descriptively.

Results: The average number of drug type per prescription at Puskesmas and Pratama clinic were 3.2 and 2.8, respectively. The prescription compliance with the national formulary at Puskesmas and Pratama clinics were $86.85 \%$ and $51.13 \%$, respectively. The average costs at Puskesmas and Pratama clinics were $\mathrm{Rp} \mathrm{5,586}$ and $\mathrm{Rp} 21,630$, respectively, and this mean difference was statistically significant $(p<0.001)$. The proportion of drug costs compared to capitation funds were $4.35 \%$ and $21.55 \%$. The 5 most used drugs at the Puskesmas were paracetamol, chlorpheniramine, cicyclic glyceril, antacids, and vitamin B complex. At Pratama clinic the 5 most used drugs were paracetamol, amoxycillin, expectorant, antacids, and omeprazole.

Conclusion: There is a relationship between prescription compliance with national formulary and average drug cost. The average percentage of drug cost to capitation at Puskesmas is lower than Pratama clinics.
\end{abstract}

Keywords: drug cost, prescription pattern, capitation, primary care

\section{Correspondence:}

Yeni. Masters Program in Public Health, Faculty of Public Health, Universitas Indonesia, Depok, West Java. Email: yeni.khalisha@gmail.com. Mobile: o82111342181.

The $6^{\text {th }}$ International Conference on Public Health

Best Western Premier Hotel, Solo, Indonesia, October 23-24, 2019 | 278

https://doi.org/10.26911/the6thicph.04.40 